\title{
A sonographic assessment of previous caesarean section scar: is a reliable safeguard for trial of labour?
}

\author{
Vandana Dhama*, Sonam Gupta, Rachna Chaudhary, Shakun Singh
}

Department of Obstetrics and Gynecology, Lala Lajpat Rai Medical College, Meerut, Uttar Pradesh, India

Received: 10 February 2020

Accepted: 03 March 2020

*Correspondence:

Dr. Vandana Dhama,

E-mail: vandanallrm@yahoo.com

Copyright: (C) the author(s), publisher and licensee Medip Academy. This is an open-access article distributed under the terms of the Creative Commons Attribution Non-Commercial License, which permits unrestricted non-commercial use, distribution, and reproduction in any medium, provided the original work is properly cited.

\begin{abstract}
Background: Over the time the caesarean delivery rate has significantly increase worldwide from $18.2 \%$ in 2002 to $30.3 \%$ in 2012. In parous women, previous caesarean section has been found to be the most common indication for caesarean delivery in as high as $67 \%$ cases. Unsecure prediction of the integrity of the scarred LUS during labor appears to be one of the reasons for high repeat caesarean rates. The purpose of this study was to assess the usefulness of sonographic measurement of the lower uterine segment scar before labour for deciding whether it is a reliable safeguard for trial of labour or not in a woman having previous one caesarean delivery.

Methods: This study was a prospective observational study, carried out on 108 pregnant women having previous one CS, gestational age $>37$, singleton pregnancy, cephalic presentation. Trans-abdominal USG was done to measure scar thickness. Trial of labour was given to each patient irrespective of scar thickness. Pregnancy outcome were noted in terms of successful VBAC or emergency LSCS and compared with scar thickness. Correlation between sonographic and intra-operative finding of scar were noted.

Results: Result shows strong correlation between scar thickness and successful trial of labour. Scar thickness increases chances of successful vaginal deliveries.

Conclusions: Sonographic assessment of previous scar has a practical application to predict the thickness and thinness of previous scar and can be taken as a reliable safeguard for trial of labour after previous cesarean but cut off value above which vaginal delivery could be considered safe is yet to be identified.
\end{abstract}

Keywords: Previous one lower segment cesarean section, Scar thickness, Vaginal birth after cesarean

\section{INTRODUCTION}

Caesarean section is a surgical procedure to deliver a baby through an incision in the uterus. Over the time the caesarean delivery rate has significantly increases Worldwide from $18.2 \%$ in 2002 to $30.3 \%$ in $2012 .^{1}$ As a result women presenting with pregnancy with previous $\mathrm{C}$-section are also rising.

Studies showed that a first successful vaginal delivery, even if instrumental, increases the chances of vaginal delivery in the subsequent pregnancy, while a first delivery by caesarean section has been associated with an increased risk of repeat caesarean Section in the subsequent deliveries.

Management of a woman, who has undergone a previous caesarean section, has been a controversial topic for a long time. In parous women, previous caesarean section has been found to be the most common indication for caesarean delivery in as high as $67 \%$ cases. $^{2}$ Unsecure prediction of the integrity of the scarred LUS during labor appears to be one of the reasons for high repeat caesarean rates. Due to the fear of uterine rupture during 
trial of labour, repeat caesarean Section is being performed by many obstetricians, sometimes without clear indications.

The old dictum - once a caesarean, always a caesarean (CRAGIN, 1916) has changed now because of the awareness among obstetricians about the safety of vaginal birth in scarred uterus as well as awareness of greater maternal morbidity and increased risk of maternal mortality in caesarean birth. ${ }^{3}$

In a woman with a single prior caesarean delivery, a trial of labour is more cost effective than an elective repeat caesarean delivery. ${ }^{4}$ According to RCOG guidelines, October 2015, planned VBAC is appropriate for and may be offered to the majority of women with a singleton pregnancy of cephalic presentation at $36+0$ weeks or beyond who have had a single previous lower segment caesarean delivery, with or without a history of previous vaginal birth except for women with previous uterine rupture or classical caesarean scar and in women who have other absolute contraindications to vaginal birth that apply irrespective of the presence or absence of a scar (e.g. major placenta previa). ${ }^{5}$

The rupture of caesarean scar is potentially devastating complication of trial of vaginal delivery which increases maternal and perinatal morbidity and mortality. Several methods ranging from postoperative echographic evaluation of uterine wound, interval hysterography, and magnetic resonance imaging to amniography have been employed to assess the integrity of scarred LUS. ${ }^{6}$

Sonographic methods can be used to evaluate the lower uterine segment thickness. LUS thickness measured by ultrasound during the third trimester of pregnancy is inversely correlated with the uterine scar rupture/dehiscence at delivery. Sonographic examination of the LUS has been used to diagnose a uterine defect and to determine the degree of LUS thinning in women with previous caesarean delivery. ${ }^{7,8}$ Taking into account clinical factors in combination with sonographic findings and careful intra-partum management could lead to increased numbers of successful VBACs with low rate of uterine ruptures.

Previous studies have demonstrated that the LUS thickness measured sonographically has a high negative predictive value for uterine rupture, suggesting that a normal LUS thickness predicts a safe trial of VBAC. However, the clinical application of LUS measurement in the management of VBAC remains controversial. ${ }^{9}$

\section{The objectives of this study were}

- To study the maternal outcome, in pregnant females who had previous one caesarean section, by sonographic evaluation of scar thickness of lower uterine segment at term as regards type of delivery
- To correlate sonographic findings with intraoperative finding

- To study the fetal outcome.

\section{METHODS}

This prospective observational study was conducted in department of obstetrics and gynecology, LLRM Medical College Meerut during one year period from 2017-2018. 108 pregnant women of gestational age at term $(>37$ weeks) were included in this study. Cases were enrolled in our study after obtaining informed consent and institutional ethical committee approval.

\section{Inclusion criteria}

- Previous one lower segment cesarean section

- Gestational age $>37-40$ weeks

- Vertex presentation

- $\quad$ Singleton pregnancy.

\section{Exclusion criteria}

- Previous 2 or more LSCS

- Absolute indication for cesarean section

- Scar on the uterus other than due to cesarean section like myomectomy, hysterotomy

- Fetal malpresentation

- Induction failure

- Congenital fetal or uterine anomaly

- Previous classical cesarean, inverted T or J shaped incision of previous section

- Multiple pregnancy

- Maternal medical disorder that may adversely affect fetal or maternal outcome

- Active labour (cervical dilatation $>6 \mathrm{~cm}$ )

- History of intake of abortificient drugs in the current pregnancy

- History of trauma in the current pregnancy

- Interval between previous caesarean and this pregnancy $<18$ months.

Detailed obstetric history with special reference to previous caesarean (its indication; preoperative, intraoperative, postoperative complications: wound sepsis; delayed stitch removal) was taken followed by general, physical, systemic and obstetrical examination. Local examination of stitch line was done for healing defects, scarring or pain. Haematological and serological investigations and obstetrical sonography were performed during antenatal visits or at the visits or at the time of admission. After going through the record related to her previous CS and careful evaluation of the patient, and sonograhic measurement of scar thickness, a trial of labor was given to every patient. No augmentation or induction was done. Patients were watched for spontaneous progression of labor. The patients were monitored carefully during labor by continuous electronic fetal monitoring. All the cases were provisionally prepared for 
emergency CS. Intra-partum monitoring was done by using the standard partograph of the World Health Organization (WHO). Continuous fetal heart monitoring was done according to WHO guidelines with the help of stethoscope, fetal heart Doppler and cardio-tocography. Four-hourly per vaginal examinations were performed to assess the progress, and special attention was paid toward the evidence of scar dehiscence or rupture. In case of any disparity, the decision of caesarean sections were taken at first indication Intra operative findings (thinned out scar, scar dehiscence and rupture) were noted down and their correlation with sonographic finding was seen.

In patients who underwent a vaginal delivery, exploration of scar was not routinely done unless there was an abnormal symptom such as excessive bleeding or pain. Following delivery fetal outcomes were noted along with neonatal assessment by a neonatologist attending each delivery.

Patients were observed for first 24 hours postpartum for primary postpartum haemorrhage. Indication of repeat caesarean was noted down along with inter delivery interval (time period between previous caesarean or VBAC and present delivery).

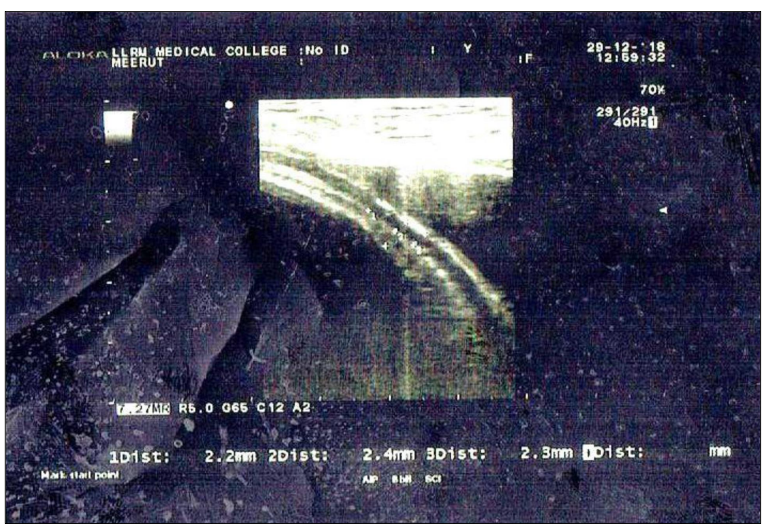

Figure 1: 3 Measurements $(1=2.2 \mathrm{~mm}, 2=2.4 \mathrm{~mm}$ and $3=2.3 \mathrm{~mm})$ smallest measurement $(2.2 \mathrm{~mm})$ was taken as lower uterine segment scar thickness.

\section{Description of imaging protocol}

All the cases were subjected to trans-abdominal sonography with moderately full bladder to create satisfactory sonographic window at term or at the time of admission, prior to the onset of active labor and without any uterine contractions by a single designated sonologist who was not aware of study design, for fetal wellbeing, placental localization and scar thickness. To measure LUS thickness 5-7 MHz trans-vaginal probe was used. The thickness of the anterior wall of LUS where it covers the fetal head was measured as a distance from urineposterior bladder wall interface to uterine wall-amniotic fluid interface. If there was no amniotic fluid, uterine wall-fetal head interface was taken (Figure 1). Two to three measurements of the thickness of anterior wall of LUS were taken in vertical plane and the lowest value measured was used to describe the thickness of LUS. All women were followed up to the time of delivery. If she did not deliver within a week, ultrasound evaluation was repeated to replace the earlier observation.

\section{Statistical analysis}

IBM statistical package for the Social Sciences, version 23 (IBM SPSS statistics Corp.; Armonk, NY, USA) was used for data analysis. Data were expressed as number, percentages or mean $\pm \mathrm{SD}$. Chi square test was used to compare between variables. $p$ value $<0.05$ was considered significant.

Primary maternal outcome was defined as mode of delivery (vaginal or caesarean). Correlation between sonographic scar thickness and intra-operative findings of scar whereas primary fetal outcome consist of Apgar score, weight of the baby and requirement of admission to NICU.

Secondary outcome of this study consist of intra-partum and postpartum hemorrhage, presence of dense adhesions during caesarean section, presence of scar rupture and scar dehiscence.

\section{RESULTS}

This study included 108 women, both booked and unbooked with a history of prior one caesarean section, irrespective of their gravida, parity and indication of previous caesarean. Demographic characteristics are shown in (Table 1).

Table 1: Demographic characteristics.

\begin{tabular}{|l|ll|}
\hline & Mean \pm SD & Range \\
\hline Age (years) & $24.23 \pm 2.62$ & $20-40$ \\
\hline Body weight & $58 \pm 2.4$ & $45-70$ \\
\hline BMI & $20.12 \pm 1.4$ & $18-24$ \\
\hline
\end{tabular}

\section{Primary outcome}

Total number of booked patients were 45 , rest were unbooked and mostly were un-investigated. Out of these 108 women, 27 (25\%) underwent successful VBAC and rest 81 landed up in emergency caesarean section. Most common indication of repeat CS was scar tenderness $(43 \%)$. Other major indications were fetal distress (22\%), non-progression of labor (19\%).

The correlation between sonographically assessed scar thickness and pregnancy outcome was given in (Table 2). This result shows strong correlation between scar thickness and successful trial of labour. It shows that as scar thickness increases chances of successful vaginal deliveries increase. 
Table 2: Correlation between sonographically assessed scar thickness and pregnancy outcome.

\begin{tabular}{|c|c|c|c|}
\hline Scar thickness (mm) & No. of patients & Successful trial of labor & Emergency LSCS \\
\hline$\leq 2$ & 16 & $1(6.25 \%)$ & 15 \\
\hline $2.1-2.5$ & 30 & $4(13 \%)$ & 26 \\
\hline $2.6-3.0$ & 38 & $9(23 \%)$ & 29 \\
\hline$>3$ & 24 & $13(54 \%)$ & 11 \\
\hline Total & 108 & 27 & 81 \\
\hline
\end{tabular}

The indication of emergency LSCS or causes of VBAC failure are given in (Table 3 ).

The correlation between intra-operative finding of scar and sonographically measured scar thickness is given in (Table 4). There were 15 patients with $\mathrm{ST} \leq 2 \mathrm{~mm}$ whose LSCS was done.

Scar was thinned out (Figure 2) in 5 cases, dehiscence (Figure 3) was present in 7 cases and there was scar rupture (Figure 4) in 3 patients.
Table 3: Indication of emergency LSCS or causes of VBAC failure.

\begin{tabular}{|ll|}
\hline Indication of emergency LSCS & No. of patients (81) \\
\hline Scar tenderness & $35(43 \%)$ \\
\hline Fetal distress & $22(27 \%)$ \\
\hline Non progression of labor & $16(19 \%)$ \\
\hline $\begin{array}{l}\text { Others (Precious pregnancy, } \\
\text { uncontrolled blood pressure, } \\
\text { 2nd stage arrest) }\end{array}$ & $8(9.8 \%)$ \\
\hline
\end{tabular}

Table 4: Intra-operative finding of scar and sonographically measured scar thickness.

\begin{tabular}{|l|l|llll|}
\hline $\begin{array}{l}\text { Scar thickness } \\
(\mathbf{m m})\end{array}$ & \multicolumn{2}{l}{ Intra-operative finding } & Dehiscence & Rupture & Total \\
\hline$<2$ & Normal & Thinned out & 7 & 3 & 15 \\
\hline $2.1-2.5$ & 0 & 5 & 4 & 0 & 26 \\
\hline $2.6-3.0$ & 5 & 17 & 1 & 0 & 29 \\
\hline$>3.0$ & 23 & 5 & 0 & 0 & 11 \\
\hline
\end{tabular}

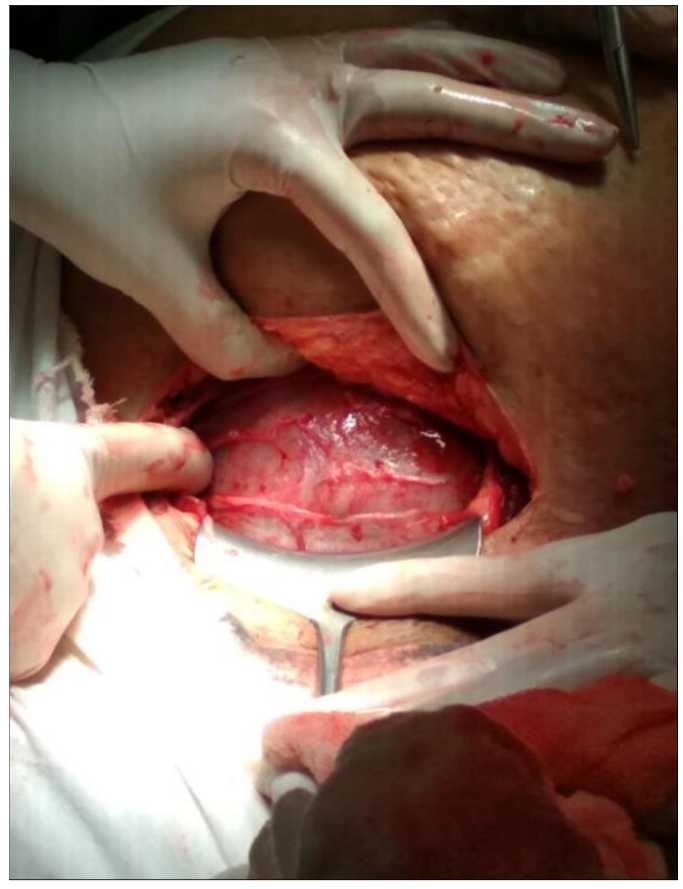

Figure 2: Thinned out lower uterine segment.

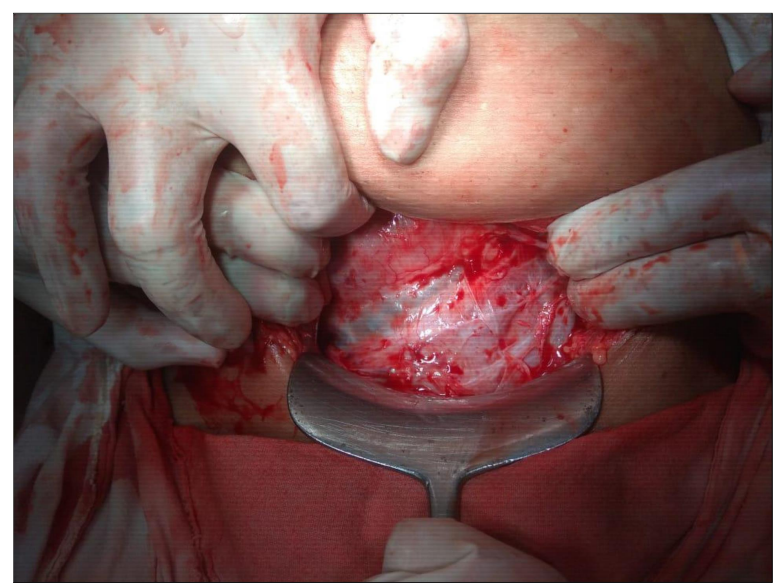

Figure 3: Scar dehiscence.

There were 26 patients with ST 2.1-2.5 $\mathrm{mm}$ who underwent LSCS. Scar was found to be thinned out among 17 patients, dehiscence was present in 4 cases and 
scar was normal in 5 patients. There were 29 cases with this ST 2.6-3 mm intra-operatively, in 23 cases scar was found to be normal. In 5 cases scar was thinned out. Only in 1 case dehiscence was seen. ST was $>3 \mathrm{~mm}$ in 11 cases. There was no thinning of scar, dehiscence or rupture was seen in any case. Scar was found to be normal intra-operatively in all of these cases.

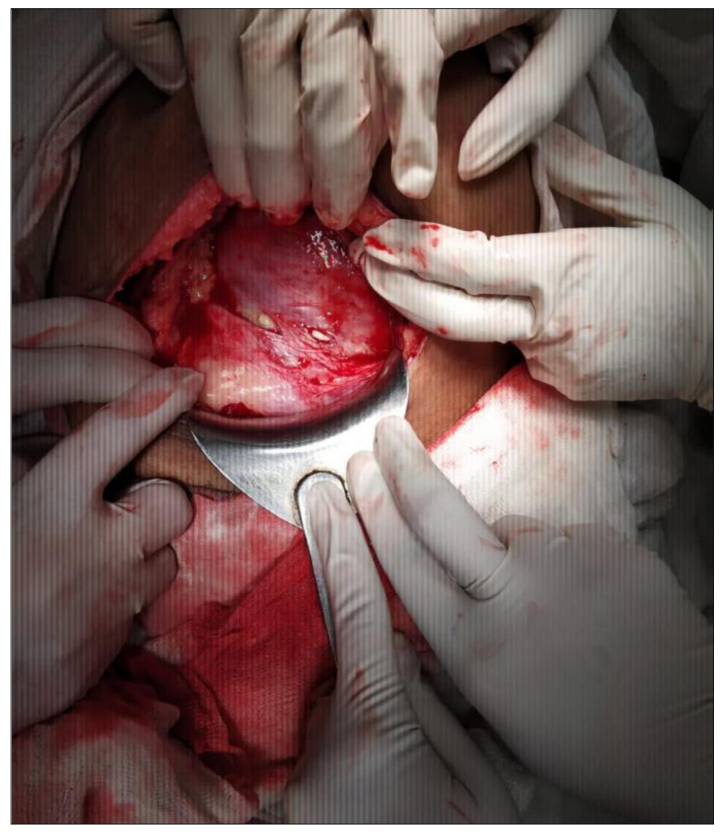

Figure 4: Scar rupture with visible fetal parts.

\section{Interval between previous $C S$ and this pregnancy}

(Inter-delivery interval)

Patients were divided in 3 groups on the basis of interdelivery interval;

- Group A - > 18-24 months

- Group B - > $24-36$ months

- Group C - > 36 months

Correlation with pregnancy outcome with respect to the inter-delivery interval was shown in (Table 5). 30 patients fell in Group A, only 3 patients delivered vaginally while rest 27 landed up in emergency LSCS. 43 patients were in Group B, in 10 patients trial of labour was successful while repeat CS was done in 33 patients. 35 patients belonged to Group $\mathrm{C}$; in 14 patients VBAC was possible while trial of labour was failed in 21 patients.

These findings gives $\mathrm{p}$ value $<0.02$, which shows strong correlation between inter-delivery interval and mode of delivery in current pregnancy? According to findings lesser the inter-delivery interval more are the chances of repeat caesarean. As this interval increases chances of vaginal birth increases. Correlation with sonographic scar thickness was shown in (Table 6).

Table 5: Correlation with pregnancy outcome with respect to the inter-delivery interval.

\begin{tabular}{|lll|}
\hline Inter-delivery interval & VBAC & EMG CS \\
\hline$>18-24$ months & 3 & 27 \\
\hline$>24-36$ months & 9 & 33 \\
\hline$>36$ months & 13 & 21 \\
\hline Total & 27 & 81 \\
\hline
\end{tabular}

Table 6: Correlation with sonographic scar thickness.

\begin{tabular}{|lllll|}
\hline $\begin{array}{l}\text { Inter-delivery } \\
\text { interval (months) }\end{array}$ & $<2$ & $2.1-2.5$ & $2.6-3.0$ & $>3.0$ \\
\hline $18-24$ & 9 & 8 & 12 & 1 \\
\hline $24-36$ & 2 & 14 & 20 & 7 \\
\hline$>36$ & 5 & 8 & 6 & 16 \\
\hline Total & 16 & 30 & 38 & 24 \\
\hline
\end{tabular}

In Group A, out of 30 patients scar thickness was $<2 \mathrm{~mm}$ in 9 patients, $2.1-2.5 \mathrm{~mm}$ in 8 patients, $2.6-3 \mathrm{~mm}$ in 12 patients and $>3 \mathrm{~mm}$ in only 1 patient.

In Group B, out of 43 patients, scar thickness was $<2 \mathrm{~mm}$ in 2 patients, $2.1-2.5 \mathrm{~mm}$ in 14 patients, $2.6-3 \mathrm{~mm}$ in 20 patients and $>3 \mathrm{~mm}$ in 7 patients. In Group C, out of 35 patients, scar thickness was $<2 \mathrm{~mm}$ in 5 patients, $2.1-2.5$ $\mathrm{mm}$ in 8 patients and $2.6-3 \mathrm{~mm}$ in 6 patients and $>3 \mathrm{~mm}$ in 16 patients. These findings give $p$ value $<0.05$, which conclude that as inter-delivery interval increases scar thickness increases.

Table 7: Apgar score at 5 minutes.

\begin{tabular}{|lll|}
\hline Apgar score at 5 minutes & VBAC & EMG CS \\
\hline 0 (IUD) & 1 & 1 \\
\hline$<3$ & 0 & 1 \\
\hline $3-5$ & 2 & 7 \\
\hline $6-8$ & 10 & 22 \\
\hline$>8$ & 14 & 50 \\
\hline Total & 27 & 81 \\
\hline
\end{tabular}

Fetal outcome was seen in terms of birth weight, Apgar score at 5 minute and requirement of NICU admission. Among 27 babies who delivered vaginally, birth weight was $>3 \mathrm{~kg}$ in 5 babies while $\leq 3 \mathrm{~kg}$, in 22 babies.

Among 81 babies who delivered by emergency LSCS birth weight was $>3 \mathrm{~kg}$ in 14 and $\leq 3 \mathrm{~kg}$ in 67 babies. $\mathrm{p}$ value was 0.8 showing no correlation between mode of delivery and birth weight. Two IUD babies were delivered, one by VBAC and one in LSCS. 10 babies were admitted in NICU, out of them two were delivered vaginally and 8 by repeat caesarean. Apgar score at 5 minute was shown in (Table 7). 


\section{Secondary outcome}

There is no correlation between gestational age and pregnancy outcome at term. Among all the patients who underwent LSCS, intra-operatively dense adhesions obstructing operative field were seen in 18 patients accounting for $22 \%$. In 2 of them bladder was adhered to anterior wall of uterus and was separated with much difficulty. In rest of the cases anterior abdominal wall was adhered to anterior wall of uterus requiring sharp dissection for separation. Scar dehiscence was seen in 12 cases i.e. $14.6 \%$. In correlation with scar thickness, it was $\leq 2 \mathrm{~mm}$ in 7 patients, $2.1-2.5 \mathrm{~mm}$ in 4 patients and $>2.5$ $\mathrm{mm}$ in 1 patient. Scar was ruptured in 3 patients in whom scar thickness was $\leq 2 \mathrm{~mm}$ in all cases babies were intrauterine and were live. In all 3 uterine repair was done and haemostasis achieved. Rupture occurred due to delayed decision taking for CS by patient's attendants. 8 patients had intra-partum haemorrhage and 15 patients had postpartum haemorrhage $(13.8 \%)$ managed conservatively.

\section{DISCUSSION}

In recent years there is a significant increase in primary cesarean section thus increasing the proportion of pregnant women with previous one cesarean section. In an attempt to reduce the rising trend of caesarean delivery worldwide, obstetrician now offer trial of labour more readily to women who have had a caesarean section. Although trial of labour is usually successful and safe, it may occasionally be associated with severe morbidity and even mortality.

This study was conducted to assess the lower uterine segment scar thickness sonographically and predicting it as a reliable safeguard for trial of labor in patient. This study showed $25 \%$ success of VBAC in 108 selected cases over 1 year. Vaginal birth after cesarean and trial of labour has been shown to reduce incidence of postpartum infection, length of hospital stay and hence, significant medical cost savings.

The tissues adjacent to the uterine scar tend to be thinner in gravida with previous CS than in those without CS. Furthermore, during labour, the descent of the fetal head may stretch the LUS further and makes the LUS thinner possibly leading to uterine rupture. Poorly healed uterine scar might affect the regeneration of isthmus of uterus and make it thinner, resulting in much thinner LUS in subsequent pregnancies. ${ }^{10}$ The most feared complication with trial of labour is rupture of scar and its associated morbidity and potential mortality for mother and/or fetus. The estimated frequency of uterine scar rupture in trial of labor is reported to be varying between 0.3 and $3.8 \%$ mainly due to lack of awareness of the integrity of scarred LUS. ${ }^{11}$

Ultrasonographic study of scar thickness proved to be a boon. Highly co-related with operative findings, sonographic evaluation of lower uterine segment is an accurate and safe procedure and is highly recommended in considering a trial of labour after previous lower segment cesarean section. ${ }^{12}$

This study assessed the LUS at term ( $>36$ weeks - 40 weeks) and engaged status of fetal head did not appear to influence the measurements. Inter-operator variability was taken care of by only one sonologist performing the measurements. The operator pressure through transducer can add to some difference in the measurements. ${ }^{13}$

Rozenberg et al, found that LUS thickness correlated inversely with the risk of rupture and concluded that thickness more than $3.5 \mathrm{~mm}$ is protective against rupture. ${ }^{14}$

In this study there was a positive correlation between intra-operative findings of the LUS and its thickness by USG. This demonstrates that lower the LUS thickness, the higher the risk of scar thinning, dehiscence and rupture. 5 patients were delivered vaginally with scar thickness $<2.5 \mathrm{~mm}$ without any adverse fetomaternal outcome. Clinical experience with the use of the LUS measurement in predicting uterine rupture and managing VBAC is limited. The cutoff value at which an extremely thin LUS on sonographic examination can predispose to a high risk of uterine rupture has yet to be identified. This obviously could not be determined in this study and in our opinion, was unable to be determined in previously reported studies because of the inconsistency in the measuring technique and the method used to diagnose uterine rupture. ${ }^{15}$

This study has suggested an inverse relationship between scar thickness, assessed sonographically, and risk of uterine dehiscence and rupture. Sonographic and intraoperative analysis shows a $\mathrm{p}$ value of $<0.05$, which is significant.

Based upon these findings, ultrasound can be used to assess the LUS and this modality can be used in third trimester 36 weeks onwards in those cases where trial of labour after previous LSCS is intended. Study findings are supported by the findings of Mohammad et al. ${ }^{16}$ One of the drawbacks of using this technique is that it is operator dependent. To overcome this problem, standardization of technique is important.

In present study, fortunately, scar dehiscence or rupture in labour was not as catastrophic as spontaneous or traumatic rupture of the uterus. However with greater care and caution the maternal and fetal mortality associated with this condition might be reduced to barest minimum.

Furthermore, finding of poorer Apgar score at one minute in the emergency cases apart from the obvious reason was because of fetal distress, the insult of labour might have contributed to the poor score. But with active 
resuscitation after delivery, these babies recovered and thus there was no significant difference at 5 minutes. This underscores the importance of alerting the neonatology team once we embark on trial of labour.

Exploration of the lower uterine segment following successful trial of labour after a previous caesarean section was not a routine practice in study centre. It is difficult to be sure whether or not the thin, soft, lower segment is intact. There is always a risk of introducing infection by the manual exploration, or of converting a dehiscence into a larger rupture. ${ }^{17}$ A reasonable compromise consist of increased vigilance in the hour after delivery of the placenta, reserving internal palpation of the lower segment for women with signs of abnormal bleeding which was not seen in any of our patient. ${ }^{18-20}$

Two factors strongly influenced the mode of delivery in this study which is:

- Previous history of VBAC- if present, chances of vaginal delivery increases

- Interval between previous cesarean and present pregnancy- longer interval is associated with more chance of vaginal delivery.

Based upon the results of this study, sonographic assessment of previous scar has a practical application to predict the thickness and thinness of previous scar. It can be performed in patients with previous scar reliably, to assess its integrity and it can be taken as a reliable safeguard for trial of labour after previous caesarean but cut off value above which vaginal delivery could be considered safe is yet to be identified. Further studies are needed to define a safe cut-off at which trial of labour after LSCS can be given.

\section{CONCLUSION}

To conclude "once a caesarean, always a caesarean" norm doesn't exist in current dates. Women with one previous caesarean section, assuming no mitigating circumstances, has option of trial of labor after a caesarean (TOLAC) with the goal of achieving VBAC and elective repeat caesarean delivery (ERCD). Success of trial of labor is not dependent only on sonographic finding but also on previous history of vaginal deliveries, inter pregnancy interval, younger patients. A cut off value above which trial of labor is absolutely safe has not identified. Fetal outcomes are more or less equal in both VBAC and repeat caesarean. Previous caesarean section has its own surgical complications. Patient should have hospital delivery in a well equipped hospital and complications should be diagnosed at an early stage so that we can prevent maternal and perinatal morbidity and mortality.

\section{ACKNOWLEDGMENTS}

Authors would like to thank Dr. Rumack CM and Dr. Callen for providing us with useful information.
Funding: No funding sources Conflict of interest: None declared

Ethical approval: The study was approved by the Institutional Ethics Committee

\section{REFERENCES}

1. Al Rifai R. Rising cesarean deliveries among apparently low-risk mothers at university teaching hospitals in Jordan: analysis of population survey data, 2002-2012. Glob Health Sci Pract. 2014;13(2):195-209.

2. American College of Obstetricians and Gynecologists (ACOG): ACOG Practice Bulletin: vaginal birth after previous cesarean 92 delivery: clinical management guidelines. Int $\mathrm{J}$ Gynecol Obstet. 2004;54:197-204.

3. Lydon-Rochelle M, Holt VL, Easterling R, Martin DP. Risk of uterine rupture during labor among women with a prior cesarean delivery. N Engl J Med. 2001;345:3-8.

4. Jha NNS, Maheshwari S, Barala S. Ultrasonographic assessment of strength of previous cesarean scar during pregnancy. Int $\mathrm{J}$ Reprod Contracept Obstet Gynecol. 2018;7:1458-63.

5. Asakura H, Nakai A, Ishikawa G, Suzuki S, Araki T. Prediction of uterine dehiscence by measuring lower uterine segment thickness prior to the onset of labor. J Nippon Med Sch. 2000;67(5):352-6.

6. Fonda J. Ultrasound specialist trainer ultrasound diagnosis of caesarean scar defects Aust J Ultrasound Med. 2011;14(3):22-30.

7. Cunningham FG, Levono KJ, Bloom SL, Spong CY, Dashe JS, Hoffman BL, et al. Prior caesarean delivery. Williams Obstetrics. 24 ${ }^{\text {th }}$ ed, New York, McGraw Hill; 2014:609-619.

8. Bujold E, Jastrow N, Simoneau J, Brunet S, Gauthier RJ. Prediction of complete uterine rupture by sonographic evaluation of the lower uterine segment. Am J Obstet Gynecol. 2009;201:320.e1-6.

9. Brill Y, Kingdom J, Thomas J. The management of VBAC atterm: a survey of Canadian obstetricians. J Obstet Gynaecol Can. 2003;25:300-10.

10. Cheung VY. Sonographic measurement of the lower uterine segment thickness in women with previous caesarean section. J Obstet Gynaecol Can. 2005;27(7):674-81.

11. Rozenberg P, GoYnet F, Philippe HJ, Nisand I. Thickness of the lower uterine segment: its influence in the management ofpatients with previous cesarean sections. Eur J Obstet Gynecol Reprod Biol. 1999;87:39-45.

12. Leung AS, Leung EK, Paul RH. Uterine rupture after previous cesarean delivery: maternal and fetal consequences. Am J Obstet Gynecol. 1993;169:94550.

13. Michaels WH, Thompson HO, Bout A, Schreiber FR, Michaels SL, Karo J. Ultrasound diagnosis of defects in the scarred lower uterine segment during pregnancy. Obstet Gynecol. 1988;71:112-0. 
14. Cheung VY. Sonographic measurement of the lower uterine segment thickness: is it truly predictive of uterine rupture? J Obstet Gynaecol Can. 2008;30:148-51.

15. Rozenberg P, Goffinet F, Philippe HJ, Nisand I. Ultrasonographic measurement of lower uterine segment to assess risk of defects of scarred uterus. Lancet. 1996;347:281-4.

16. Sen S, Malik S, Salhan S. Ultrasonographic evaluation of lower uterine segment thickness in patients of previous cesarean section. Int J Gynaecol Obstet. 2004;87(3):215-9.

17. Cheung Y. Sonographic measurement of the lower uterine segment thickness: Is it truly predictive of uterine rupture? J Obstet Gynaecol. 2009; 113:520.

18. Fukuda M, Fukuda K, Mochizuki M. Ultrasound assessment of lower segment thickness during pregnancy, labour, and the postpartum period. J Obstet Gynecol Can. 2016;38:134-40.

19. Gotoh H, Masuzaki H, Yoshida A, Yoshimura S, Miyamura T, Ishimaru T. Predicting incomplete uterine rupture with vaginalsonography during the late second trimester in women with priorcesarean. $\mathrm{J}$ Obstet Gynecol. 2000;95:596-600.

20. Farmer RM. Uterine ruptures during trial of labour after previous caesarean section. Am J Obstet Gynecol. 1991;165:996-1001.

Cite this article as: Dhama V, Gupta S, Chaudhary R, Singh S. A sonographic assessment of previous caesarean section scar: is a reliable safeguard for trial of labour?. Int J Reprod Contracept Obstet Gynecol 2020;9:1520-7. 